Document downloaded from:

http://hdl.handle.net/10251/150454

This paper must be cited as:

Mehmood, A.; Khan, S.; Shams, B.; Lloret, J. (2015). Energy-Efficient Multi-Level and Distance-Aware Clustering Mechanism for WSNs. International Journal of Communication Systems. 28(5):972-989. https://doi.org/10.1002/dac.2720

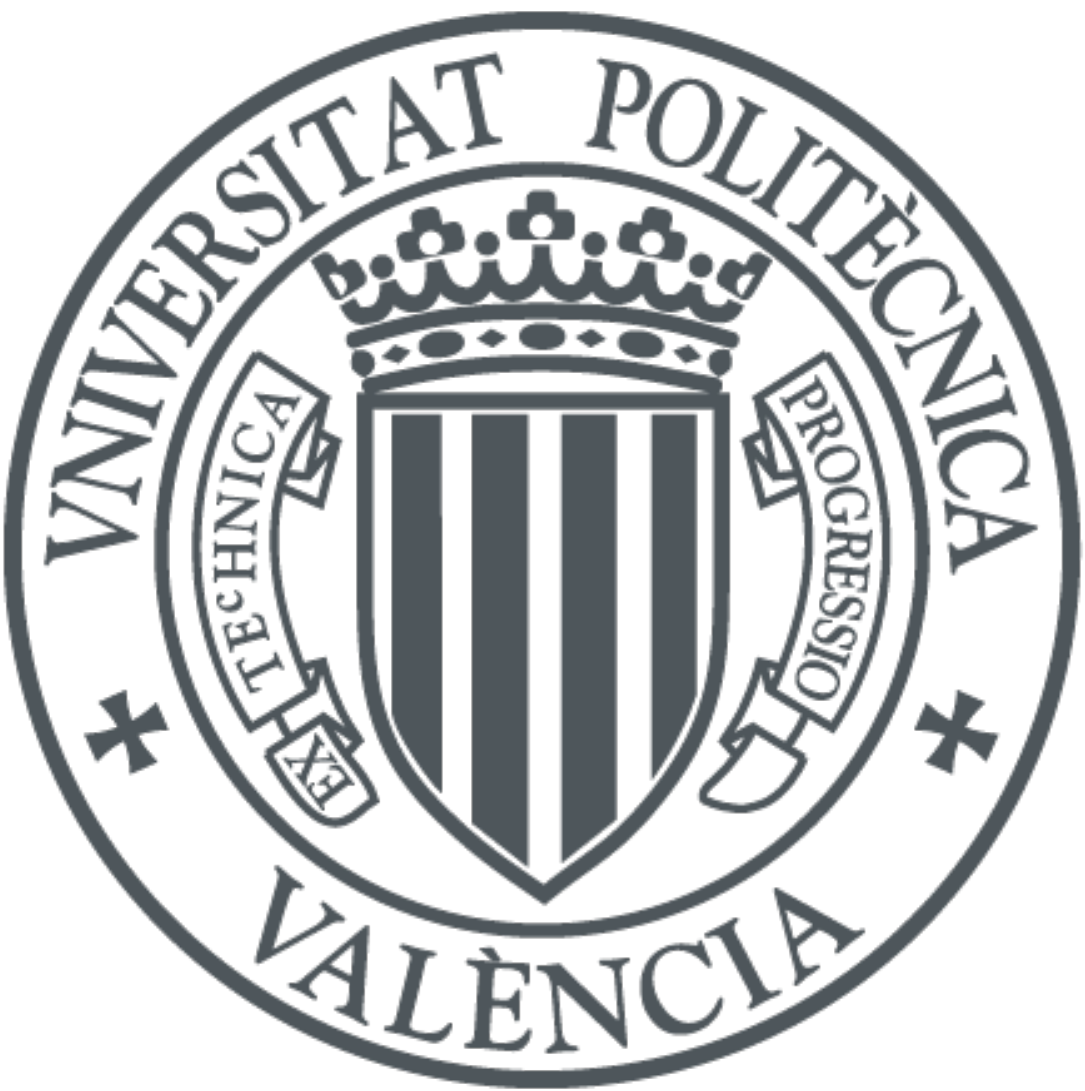

The final publication is available at

https://doi.org/10.1002/dac.2720

Copyright John Wiley \& Sons

Additional Information 


\title{
Energy-Efficient Multi-Level and Distance-Aware Clustering Mechanism for WSNs
}

\author{
Amjad Mehmood ${ }^{1}$, S. Khan ${ }^{2}$, Bilal Shams ${ }^{3}$, Jaime Lloret ${ }^{4}$ \\ 1, 2, 3 Institute of Information Technology, Kohat University of Science \& Technology, Pakistan \\ ${ }^{4}$ Integrated Management Coastal Research Institute, Universidad Politecnica de Valencia, Spain \\ 1 amjadiitkust@gmail.com, ${ }^{2}$ skhan@kust.edu.pk, ${ }^{3}$ bilal.shams@gmail.com, ${ }^{4}$ jlloret@dcom.upv.es
}

Most sensor networks are deployed at hostile environments to sense and gather specific information. Since sensor nodes have battery constraints, therefore, research community is trying to propose energy efficient solutions for wireless sensor networks (WSNs) to prolong the lifetime of the network. In this paper, we propose an energy efficient multi level and distance aware clustering (EEMDC) mechanism for WSNs. In this mechanism the area of the network is divided into three logical layers, which depend upon the hop-count based distance from the base station. The simulation outcomes show that EEMDC is more energy-efficient than other existing conventional approaches.

Keywords: Energy-Efficient, Clustering, Multi-Level, Distance-aware, Routing, WSN

\section{INTRODUCTION}

WSN consists of hundreds of thousands of small-size, low-cost nodes wirelessly connected. It converts physical world into digital world. Each node has limited processing capability, low memory and battery supply [1]. Once deployed, each node uses its energy for sensing, receiving, storing and communication. As nodes are deployed at harsh environments, therefore, it is not realistic to refresh or restore the batteries. There are many limitations in the WSNs such as power-utilization, energy-utilization, robustness, sensing-coverage, organization, energy- 
harvesting, and security. The WSNs are usually application specific. The most important applications of WSNs are military, environment monitoring, agricultural activities, sound, temperature, and water applications Moreover, there are many researchers focused on sensor tracking and localization algorithms [2-4].

In WSN, network energy-preservation is a very hot issue. Due to the inherent nature of the wireless channel, nodes in WSN broadcast their sensed data to their neighbors, which in turn rebroadcast data until they reach the base station (BS). However, these broadcasting and rebroadcasting processes consume more energy. As a result, nodes' life-time in the whole set-up is decreased. To fix the issue, researchers started to use several techniques such as virtual rings [5], collaborative MAC techniques [6], and group-based topologies [7], which group nodes into clusters [8]. Some authors have demonstrated that cluster-based techniques are more energyefficient than regular ones [9]. Moreover, we can find in the related literature some free clustering systems [10], parameter-based clustering systems [11], and cluster-based routing protocols [12].

In clusters, one node becomes the Cluster Head $(\mathrm{CH})$ and the others are the cluster members. $\mathrm{CH}$ congregates the information from its members, and sends the information directly to the BS in case of a single-hop. While in case of a multi-hop, it drives it to the next $\mathrm{CH}$, which in turn adds its own data and sends it to the next $\mathrm{CH}$. This process is repeated till data reach the BS.

A lot of cluster-based protocols have been introduced by the research community. The clustering protocols in WSN can be categorized as shown in Table 1.

\begin{tabular}{|l|l|}
\hline Feature & Options \\
\hline Clustering Technique & Distributed, Centralized, Hybrid \\
\hline Network Planning & Single-hop, Multi-hop \\
\hline Clustering intention & Energy efficiency, Coverage, load balancing, Fault-tolerance \\
\hline
\end{tabular}




\begin{tabular}{|l|l|}
\hline CH Selection Process & Random, Deterministic \\
\hline Intra-Cluster topology & Fixed, Adaptive \\
\hline
\end{tabular}

Table 1: Clustering Protocols Categorization Parameters

In order to save energy, most of these routing protocols work in rounds. It has been proved by many works that it is an efficient way to save energy [13]. Each round is made-up of a Set-up phase and a Steady phase. The Set-up phase consists of cluster set-up, topology construction, $\mathrm{CH}$ announcement, cluster member acknowledgement to specific $\mathrm{CH}$, and TDMA schedule creation. Whereas in Steady phase data transmission process is carried out from members to the $\mathrm{CH}$ of each cluster, from $\mathrm{CHs}$ to relay $\mathrm{CHs}$, and finally data reaches the BS as shown in Figure 1.

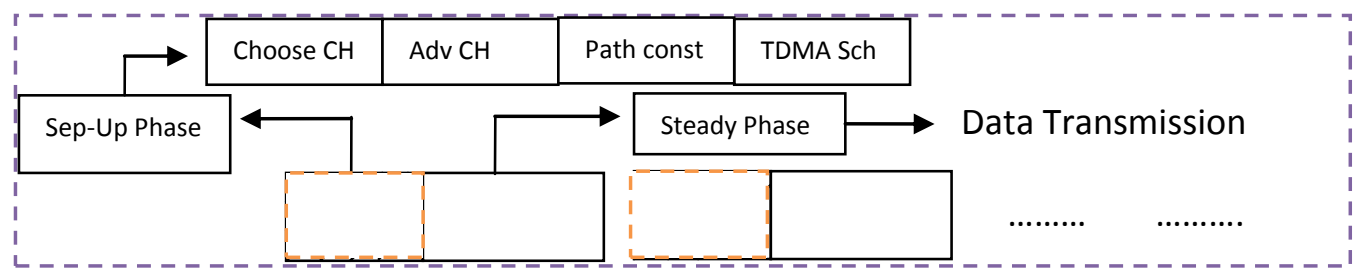

Figure 1: LEACH Protocol's Round Details (Adv CH: Advertisement advertise by CH, TDMA Sch: TDMA Schedule)

In order to increase the energy-efficiency in the communication protocol, we propose a clusterbased protocol entitled as EEMDC which merges some of the characteristics of some existing works. The system divides the network area intro three logical layers (obtaining a hierarchical structure, which allows to configure IPv6 address easily [14]), and takes into account the hopcount value of the nodes with regard to the BS in order to let the new node join a particular layer. Then, it calculates the average of outstanding energies divided by the hop-count values of the nodes in a cluster for the selection of the $\mathrm{CH}$. It avoids clusters overlapping by taking care that each node joins only one cluster at a time. Moreover, it avoids idle lessoning due to the fact of introducing levels in the clustering, so the nodes of the particular level become active when their turn arrives and sleep otherwise. Finally, the system performs data fusion in sequence in order to save energy. 
The reminder of the paper is as follows. Section 2 presents the related work and our motivation to carry out this work. The protocol proposal operation is explained in Section 3. Section 4 presents some protocol simulations and contrasts our proposal with some well know protocols. Finally, Section 5 draws the conclusion and future work.

\section{RELATED WORK AND MOTIVATION}

The cluster-based protocols add more robustness, adaptability, scalability, flexibility, energyefficiency in finding routes and easy to manage [15-18] as compared to flat, tree, grid and PEGASIS based protocols in WSNs. That's why the research community has proposed a large number of cluster based solutions for WSNs. In this paper authors are going to briefly explain the related protocols for discussion and compare them with the proposed protocol.

Mohammad Zeynali et al. worked on a novel technique called Hierarchical Routing Protocol (HRP) in-sequence to extend the lifetime of the network [19]. In this protocol, a routing tree is built on CHs for transporting aggregated data to the BS. In [20], J. Chen et al. suggested a multihop protocol where cluster's sensor nodes select a coordinator. Coordinators are divided into a number of disjoint groups. One of the coordinators is chosen as a $\mathrm{CH}$ of this group. Hence the sensed data is routed through sensor nodes to their coordinator, from the coordinator to their head, and from the head to the BS.

LEACH (Low Energy and Adaptive Clustering Hierarchy) is a completely distributed protocol [21]. It consists of three phases. They are called advertisement, set-up, and steady phase. It gives a chance to all nodes in the cluster to become a $\mathrm{CH}$. Therefore, this protocol is called as justice protocol. In this protocol, there is a threshold value to be checked for the selection of the CH. I.e. 
the protocol assigns a random value of $n$ such that $0<n<1$, if $n<T(n)$. This means that a node is selected as $\mathrm{CH}$ for this particular round.

Gurprat Sign Chhabra et al. proposed a blend of cluster and tree based approach to enlarge the network lifetime by improving the FND (First Node Death) in [22]. Aimin et al. presented the enhanced version of Low Energy Adaptive Clustering Hierarchy (LEACH) by means of selecting the $\mathrm{CH}$ on the basis of the outstanding-energy of the nodes dynamically [23]. As in traditional $\mathrm{LEACH}$, the number of $\mathrm{CHs}$ remains unchanging throughout the network lifetime, but in the improved version it is made variable according to the number of live nodes in the network. Consequently, simulation consequences show an upgrading for First Node Dies (FND) and Half of the Nodes Alive (HNA) over traditional LEACH.

In [24], Gou et al. introduced the Partition based LEACH (pLEACH). In this protocol, node having highest residual-energy is selected as $\mathrm{CH}$ in each subdivision. Each node knows its location information, which means that that the system is designed to provide location services in the network.

Ding et al. proposed a well-organized clustering protocol based on each node weight considered on its energy and its distance from its neighbors [25]. The node having more weight is selected $\mathrm{CH}$. This technique also improves the network lifetime. Coly et al. [26] proposed a protocol which works in distributed and randomized manner to arrange the nodes into clusters. So, in order to save the energy, member nodes drive the sensed data to the $\mathrm{CH}$. Aubin Jarry et al. [27] suggested to maximize the network lifetime and routing of data to the BS by balancing the energy utilization amongst the nodes of the network. Yi-huazhu et al. [28] proposed (ERAPL) an 
energy-efficient routing mechanism to dynamically make longer the network lifetime while it is being consumed efficiently.

In [29], Hana Khamfroush et al. suggested a multi-hop protocol in which predefined nodes, having greatest outstanding energy, are elected as $\mathrm{CH}$ first, and then the members of every cluster are determined on the basis of their distance involving the nodes and the $\mathrm{CH}$ and also $\mathrm{CH}$ and the BS. Li et al. projected an imbalanced clustering technique to increase the network lifetime by two or three times the one accomplished in the most excellent imbalanced clustering approach [30].

Noman Aslam et al. [31] proposed a distributed protocol in which nodes take decisions based on the local information. S.Yi et al. [32] suggested PEACH (Power efficient and adaptive clustering hierarchical) protocol to form a multi-level clustering system. It improves the lifetime of the motes in the network. Pei at el. suggested DECSA stands for Distance-Energy Cluster Structure Algorithm [33]. It is based on LEACH clustering protocol. It considers distance between the nodes, the distance of the base station, and outstanding energy of nodes. It divides the network into three levels, in order to reduce the energy consumption of the CHs. It saves the energy by avoiding the direct communication between the $\mathrm{CHs}$ and the BS.

MTE protocol, proposed by Weng et al. [34], has exhibited less energy utilization and has enlarged the network lifetime by sending data to a path consuming minimum transmission energy. In this protocol, nodes' remaining energy has not been considered for the selection of the $\mathrm{CH}$. Therefore, it could lead to assign the cluster head role to a node which does not have enough energy. So it could deplete its energy earlier than others. Hence it decreases network lifetime. Other problem with LEACH is that every $\mathrm{CH}$ sends its information to the BS directly, which is again impractical in case of a large WSN. Thus LEACH doesn't take care of outstanding-energy 
and the distance of the $\mathrm{CH}$ to the BS. Hybrid Energy Efficient Distributed (HEED) clustering is a single-hop approach [35]. Selection of $\mathrm{CH}$ is based on remaining-energy and the degree of nodes in a cluster. D. Kumar et al presented Energy efficient heterogeneous clustered scheme for wireless sensor networks (EEHC) [36]. In the protocol it assumed that all the nodes are homogeneous in nature, and deployed randomly in the environment. Each node has the opportunity to become $\mathrm{CH}$ on the basis of the residual energy it has. Kim et al presented Treebase Clustering Protocol (CBT) for WSN [37]. In the protocol as its name suggests, nodes form tree in the cluster, with $\mathrm{CH}$ as their root. The height of the tree is determined on the basis of distance of the nodes from the $\mathrm{CH}$. Then $\mathrm{CH}$ sends data to the BS using single-hop method. J. $\mathrm{Yu}$ has presented EADC protocol [38], in which $\mathrm{CH}$ sends data to the BS by considering the threshold value. If the $\mathrm{CH}$ distance is less than threshold value then it sends it directly to the $\mathrm{BS}$, otherwise selects the $\mathrm{CH}$ having more outstanding energy as a rely $\mathrm{CH}$ for sending data to the BS. M. Ye et al presented an Energy Efficient Clustering Scheme (EECS) [39], which is preferred for the applications of periodical data gathering. In the protocol the $\mathrm{CH}$ is elected on the basis of outstanding energy of the nodes, moreover it achieves well $\mathrm{CH}$ distribution. Therefore it improves the lifetime of the whole network.

Dynamic Clustering and Distance Aware Routing Protocol (DDAR) [40] is the one in which the energy consumption is controlled by considering remaining energy, distance and dynamic number of $\mathrm{CHs}$ in the network. In the setup phase all nodes forward their position and outstanding-energy to the BS. BS then finds the best possible number of $\mathrm{CHs}$ on the basis of available nodes in the network. Table 2 summarizes the state of the art of energy-aware cluster based routing protocols. All studied protocols are deployed for stationary nodes. The purpose of all of them has been the energy conservation. Moreover, it is considered a variable number of 
clusters and the initial $\mathrm{CH}$ selection is random. All of them are a single-hop intra-cluster topology.

\begin{tabular}{|c|c|c|c|c|c|c|c|}
\hline $\begin{array}{c}\text { Clustering } \\
\text { protocol }\end{array}$ & $\begin{array}{c}\text { Clustering } \\
\text { methods }\end{array}$ & Routing Type & Cluster Size & $\begin{array}{c}\text { Energy } \\
\text { Efficiency }\end{array}$ & Additional features & $\begin{array}{c}\text { Location } \\
\text { awareness }\end{array}$ & $\begin{array}{c}\text { Connectivity of } \\
\text { CH to BS }\end{array}$ \\
\hline HRP [19] & Distributed & Cluster based & variable & Good & Load Balancing & No & Multi-hop \\
\hline ECHS[20] & Distributed & Cluster based & variable & Good & Load Balancing & No & Multi-hop \\
\hline LEACH [21] & Distributed & Cluster based & variable & Very Low & Load Balancing & No & Direct Link \\
\hline GDP[22] & Centralized & $\begin{array}{c}\text { Cluster based and } \\
\text { Tree based } \\
\end{array}$ & variable & Good & Load Balancing & Yes & $\begin{array}{c}\text { Minimum } \\
\text { spanning tree }\end{array}$ \\
\hline pLEACH [24] & Distributed & Cluster based & variable & Good & Load Balancing & $\begin{array}{c}\text { Both } \\
\text { Yes/No } \\
\end{array}$ & Direct Link \\
\hline DWEHC[25] & Distributed & Cluster based & variable & V. High & Load Balancing & No & Direct Link \\
\hline COCA [29] & Distributed & Cluster based & Equal size & Good & Load Balancing & No & Multi-hop \\
\hline PEACH[32] & Centralized & Cluster based & variable & Good & Load Balancing & Yes & $\begin{array}{c}\text { One hop } \\
\text { Communication }\end{array}$ \\
\hline DECSA[33] & Distributed & Cluster based & variable & Good & Load Balancing & No & Multi-hop \\
\hline MTS [34] & --- & $\begin{array}{c}\text { Flat Routing } \\
\text { based }\end{array}$ & -- & Very Low & ---- & ---- & ------ \\
\hline HEED [35] & Distributed & Cluster based & variable & Moderate & Load Balancing & No & Direct Link \\
\hline EEHC[36] & Distributed & Cluster based & variable & Good & Load Balancing & No & Direct Link \\
\hline ТВС [37] & Distributed & Random & Cluster based & Single-hop & variable & Good & Direct Link \\
\hline EADC[38] & Distributed & Cluster based & Equal size & Good & Load Balancing & No & Multi-hop \\
\hline EECS[39] & Distributed & Cluster based & variable & V. High & $\begin{array}{l}\text { load balancing / } \\
\text { periodical data } \\
\text { communications }\end{array}$ & No & Direct Link \\
\hline DDAR [40] & Centralized & Cluster based & variable & Good & Load Balancing & Yes & Multi-hop \\
\hline LEACH-C[41] & Centralized & Cluster based & variable & Moderate & Load Balancing & Yes & Direct Link \\
\hline
\end{tabular}

Table 2: Summary of the most important features of the routing protocols included in this section

Our technique is motivated by the research of Gautam et al. in [40]. They considered that clusters close to the BS consume more energy than those away from the BS. As those nodes do the job of relaying near the BS, their death chances are high [21, 33]. It leads to the Funnel Effect [35]. Therefore, our proposed EEMDC divides the network into logical layers with respect to distance from the BS.

\section{EEMDC OPERATION}


The nodes near the BS carry higher load of traffic than the nodes far away from the BS [42]. Therefore, the nodes near the BS drain off their energy earlier then nodes away from the BS. Hence, the lifetime of the network decreases. In order to increase the network lifetime, we propose a technique called Energy Efficient Multi level Clustering and Distance Aware Mechanism (EEMDC) for the cluster set-up, steady phase and routing process. This technique is based on considering the nodes placement with regard to the BS in the network, for cluster-setup, steady-phase, and routing process, using hop-count value. EEMDC characteristics include:

- Hybrid clustering process

- Overwhelms the hotspot problem using multi-level distance aware clustering with regard to the BS

- Random CH selection process through average of residual-energies by average hop-count values

- Minimum multi-hop Inter-cluster connectivity

- Energy-efficiency

- Load-balancing

- Scalability

- Adaptive intra-cluster topology

EEMDC protocol works in rounds like many well-known data gathering protocols such as Low Power Efficient Adaptive Clustering Hierarchical (LEACH), Centralized Low Power Efficient Adaptive Clustering Hierarchical (C-LEACH), and Dynamic Distance Aware Routing (DDAR), Hybrid Energy Efficient Distributed Clustering Approach protocols.

In order to fix the hotspot nodes problem and balance the workload of the network, EEMDC protocol divides the network into three logically levels. First Level Clusters (FLC) includes 
nodes having a hop-count value of "one" and "two", while Second Level Clusters (SLC) includes nodes having a hop-count value of "three", "four" and "five", and, finally, Third Level Clusters (TLC) contains nodes having a hop-count value of "six" and above. The discrepancy of nodes in each level of clusters is due to their position with respect to the BS. Hence, FLC contains more clusters and fewer members in each cluster. At the same time, SLC has lower number of clusters and more members than in SLC, and, lastly, TLC has lower number of clusters and more members as compared to SLC. In the EEMDC cluster formation process, BS broadcasts a cluster-initiative packet containing the hop-count value to all its neighbor nodes in the network. The hop count value parameter in the packet helps the node to determine its distance from the BS. So, on the basis of hop-count value, each node decides on which cluster level is going to be part of (e.g. FLS, SLC or TLC). After the beacon packet reaches, each node calculates its level. Hence the protocol starts working distributed.

BS sends the starting packet to its neighbors. The neighbors increment their hop count value only when the packet is received for its first time or when update messages are received. Then, they broadcast the new value to their neighbors. Then, their neighbors repeat the same process, and finally each node gets its position with regard to the BS, and the level of cluster it belongs to.

In the EEMDC cluster set-up phase, each node has equal energy at the beginning like LEACH [21]. Therefore, CHs are nominated randomly in the first round without considering the reminding energy of the cluster nodes, but in next rounds, $\mathrm{CH}$ nomination decision takes place on the basis of the reminding energies and the hop count values in the cluster. Each node sends its reminding energy and hop count value to its neighbors in its cluster. After that, each node in the cluster performs an average operation on the sum of remaining energies and hop count values. Let $E_{i j}$ be the remaining energy of node $j$ in the cluster $i$, and let $d_{i j}$ be the hop count value 
of node $j$ in the cluster $i$. The average remaining energy of the cluster $i\left(E_{i}\right)$ and the average hop count value of the cluster $i\left(d_{i}\right)$ is given by equations 1 and 2 respectively.

$$
\begin{aligned}
E_{i} & =\frac{\sum_{j} E_{i j}}{j} \\
d_{i} & =\frac{\sum_{j} d_{i j}}{j}
\end{aligned}
$$

When a node has its remaining energy divided by the hop count value is greater than the average reminding energies divided by the average hop count values of the neighbor's node in a cluster, then that node is chosen as $\mathrm{CH}$. This is analytically expressed as equation 3 .

$$
\frac{E_{i j}}{d_{i j}}>\frac{E_{j}}{d_{j}}
$$

In case of having two or more nodes in the same case, node with lower hop count value is selected as $\mathrm{CH}$. All other nodes will be regular nodes in the cluster.

Once a node gets nominated for $\mathrm{CH}$, it sends a joining message to its neighbors. Neighbors decide to join a specific $\mathrm{CH}$ based on the hop-count value as it has been explained before. The node, which receives the joining message from two or more $\mathrm{CHs}$ of different levels, joins the cluster according to the level of the cluster it belongs to, but if it gets the joining message from two or more clusters from the same level, then it selects the one with highest received signal strength. Hence, this process avoids the overlapping of clusters in the same and different levels which sequentially mount-up the network lifetime.

Once the $\mathrm{CH}$ receives the acknowledgement of the joining packet, it assigns the TDMA schedule to its members. So, the members drive their data packet to the concerned $\mathrm{CH}$ without interruption. As WSN consists of large number of nodes therefore, fixing the IDs on the nodes before the deployment of the network is impractical in large WSNs [31], hence the node identification mechanism in EEMDC is as follows. $\mathrm{CH}$ adds one byte at the end of its ID and 
assigns it to its neighbors. Similarly, its neighbors add one byte and assign it to its neighbors, and so on. By using such technique node identification process is carried out. Therefore this technique is considered more practical and also helps to keep away from redundant information to increase the nodes' lifetime. In multi-level cluster, when the lower level of nodes is collecting information from its environment the next level of nodes are sleeping at that time [43] (see figure 2). This avoids channel idle-listening and hence saves energy to the cluster members.

We have designed our WSN without allowing regular cluster members having connections with regular cluster members from other clusters. So, nodes, which are able to see nodes of other clusters, will not establish a connection with them. When a node finds a node that is not from its cluster, it simply drops such communication and hence saves its transmission power.



Figure 2: Message Flow in a Cluster (FLC) 
Once the set-up phase of the clusters is finalized, $\mathrm{CH}$ assigns the TDMA slot to its 1-hop neighbors. 1-hop neighbor adds some constant value and assigns TDMA slot to 2-hop neighbors. Similarly, TDMA schedule is distributed among the clusters according to their cluster level.

In order to avoid the hotspot problem we will try to maintain with small size the clusters close to the BS (i.e. nodes which belong to the FLC). Moreover, nodes in the hub have more chances to exhaust their energy earlier than the nodes far away from the BS belong to the SLC, and remaining nodes belong to the TLC. Figure 3 shows the cluster levels.

In the steady phase, each low level cluster gets the data from its environment and relays the information to its next level and hence data reaches the cluster head where data fusion and aggregation [44-47] is done, fused data is directed to BS through the shortest path using relay clusters.

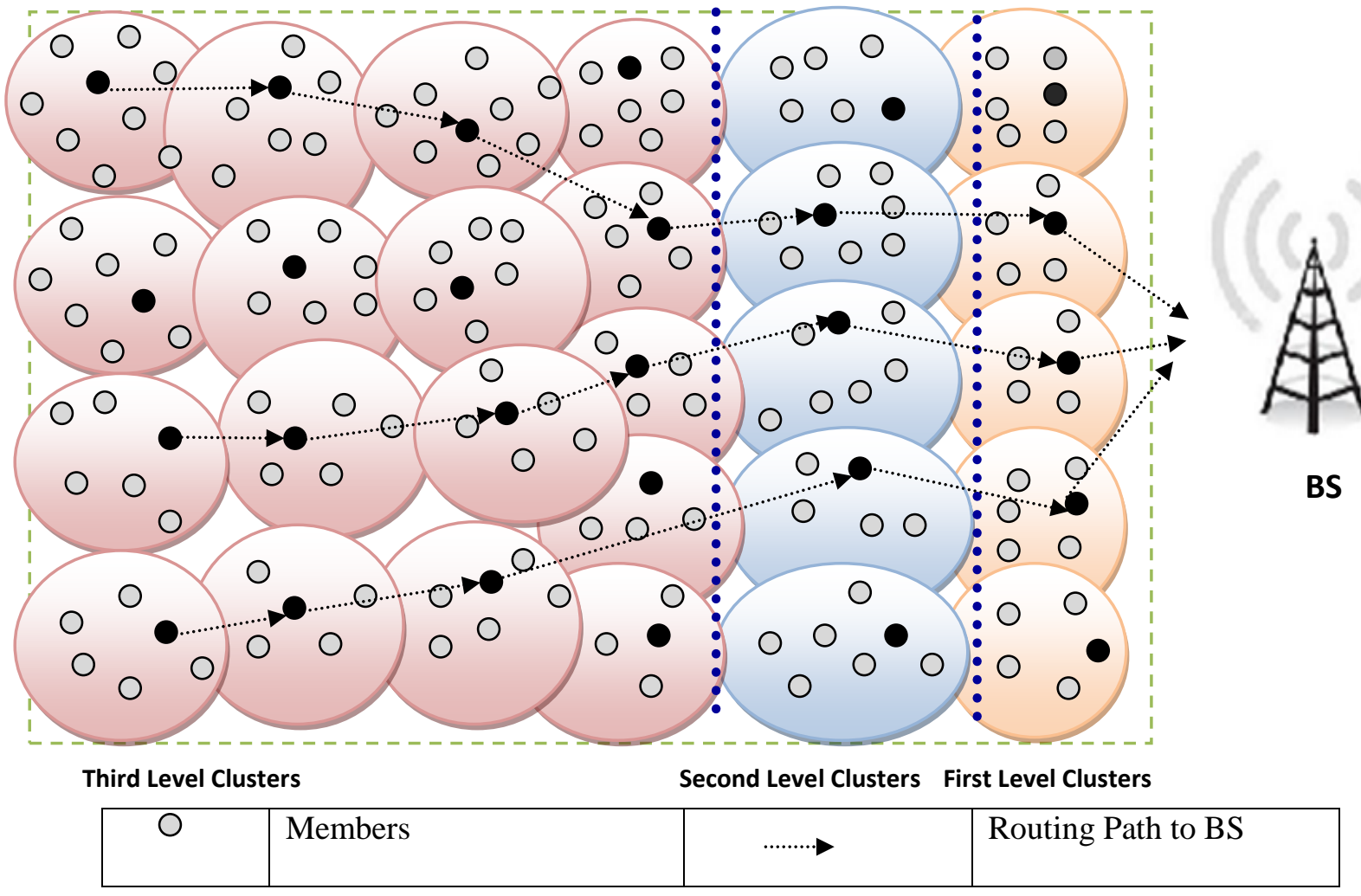




\begin{tabular}{|l|l|l|l|l|}
\hline- & Cluster Heads & & $\begin{array}{l}\text { Logical Cluster level } \\
\text { Representation }\end{array}$ \\
\hline$($ 角 & Base Station (BS) & $\bigcirc \bigcirc \bigcirc$ & $\begin{array}{l}\text { Represents first, second, } \\
\text { third level clusters }\end{array}$ \\
\hline
\end{tabular}

Figure 3: EMCDR Protocol's Logical Division in Levels (TLC, SLC, FLC)

\subsection{DATA TRANSMISSION FROM CLUSTER HEAD TO THE BASE STATION}

Routing data from the $\mathrm{CH}$ to $\mathrm{BS}$, after performing the aggregation, is performed using the following technique. If $\mathrm{CH}$ belongs to the FLC, it sends the data to the BS directly without considering any relay clusters. But if the cluster belongs to the SLC or TLC, CH considers the minimum hop-count value of the available $\mathrm{CHs}$ in its neighbor set. Then, it sends the data to a specific $\mathrm{CH}$ taking into account the minimum hop-count value.

Similarly, the cluster receiving the data uses the same procedure and sends the data to its neighbor cluster taking into account the minimum hop-count value and so on. Hence the data reaches the BS using minimum hop of relay clusters.

\subsection{FLOWCHART OF THE EEMDC OPERATION}

EEMDC starts from the BS. It sends a packet to its neighbors, which contains the hop-count value. Each node calculates its hop-count value and consequently gets the cluster-level information as shown in figure 4. Once each node gets these two parameters, the protocol enters into the steady phase. In the steady phase, it checks that if the round value is 1 , then $\mathrm{CH}$ is elected randomly because it is understood that each node has the same energy at the beginning. In case of a second round, each node shares its reminding energy and hop count value with its neighbors. Hence, each node is aware of the reminding energies and hop count values in the cluster. Therefore, each node computes equation 3 and a $\mathrm{CH}$ is elected based on the explained 
procedure. Once the $\mathrm{CH}$ is elected, it announces itself as $\mathrm{CH}$ to the nodes in the cluster. The nodes in the cluster acknowledge the request sent by the $\mathrm{CH}$. Then, the $\mathrm{CH}$ sends a discovery message to discover CHs. When the node collects replies from two or more $\mathrm{CHs}$ from the same level, then, it joins the best $\mathrm{CH}$ based on the received signal strength. But, if it receives replies from two or more CHs from different levels, then it takes a decision based on the cluster level, which is saved on each node. Hence, a $\mathrm{CH}$ must establish connections with a $\mathrm{CH}$ of the same level. 




Figure 4: Flowchart of EMCDR Working 
Once the $\mathrm{CH}$ and the regular nodes $(\mathrm{CM})$, belonging to the cluster, have taken a decision, the $\mathrm{CH}$ sends the TDMA schedule among the nodes in the cluster in order to send their sensed data to the $\mathrm{CH}$ without interruption.

Once the nodes receive the TDMA schedule, they start sending their sensed data to the $\mathrm{CH}$, and the $\mathrm{CH}$ performs the aggregation of the sensed data to fuse them. Hence, $\mathrm{CH}$ transmits its fused data to the neighbor $\mathrm{CH}$ that has less hop count value to the BS. The neighbor $\mathrm{CH}$ sends its fused data to its neighbor $\mathrm{CH}$ that has the lowest hop count value and so on. Consequently data finally reaches the $\mathrm{BS}$.

Figure 5 explains how the BS sends the packet containing the hop count value to the nodes in the network. Every node checks whether it is getting the message for the first time or not. If the node has received the message before, then it simply discards the packet. Alternatively, if the node has not received the message before, then it records the hop count value, increments it, puts the new value in the packet, and broadcast it to its neighbors (except to the one from it was received). The same process is repeated by their neighbors and hence each node records its hop count value. Then, the cluster level decision is taken because it is based on the hop-count value saved at each node.

Hence, after the execution of the initialization phase, each node gets its position in terms of hop count to the BS. Finally, all nodes know at which cluster level it belongs to. 


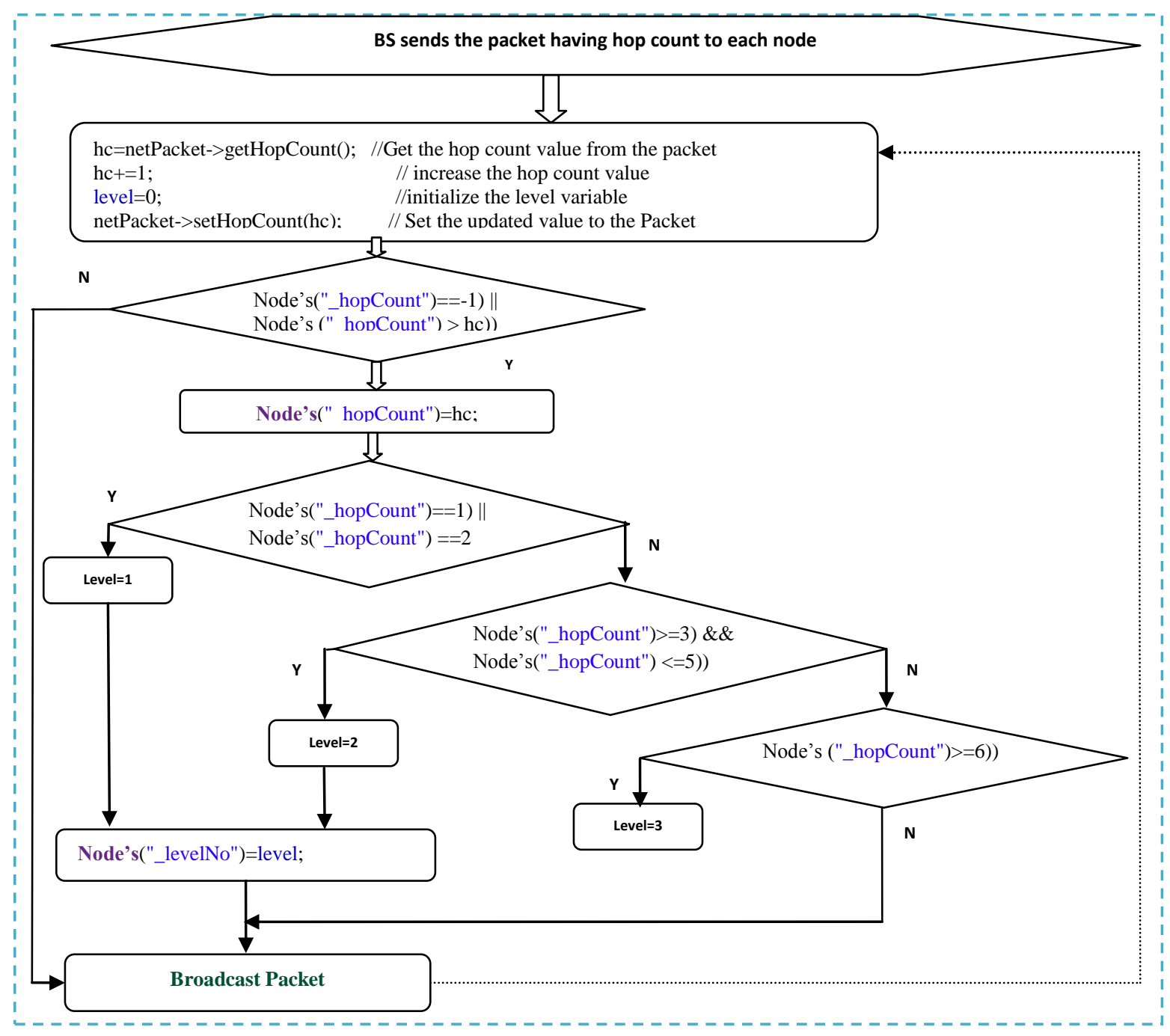

Figure 5: Calculate hop count and cluster level

Figure 6 illustrates the aggregation performed by the $\mathrm{CH}$ on the sensed data received from the nodes. It checks that if the $\mathrm{CH}$ belongs to the FCL, then it sends the data to the $\mathrm{BS}$ directly because it is close to the BS. But if it belongs to SLC or TLC, then that $\mathrm{CH}$ has to send the data through relay clusters before reaching the BS. Therefore, $\mathrm{CH}$ selects the next cluster head in the network as a relay $\mathrm{CH}$ which has smallest hop count value because it is believed that it is close to the BS. Using the same technique of selecting the minimum number of relay $\mathrm{CHs}$, data finally reaches the BS. 


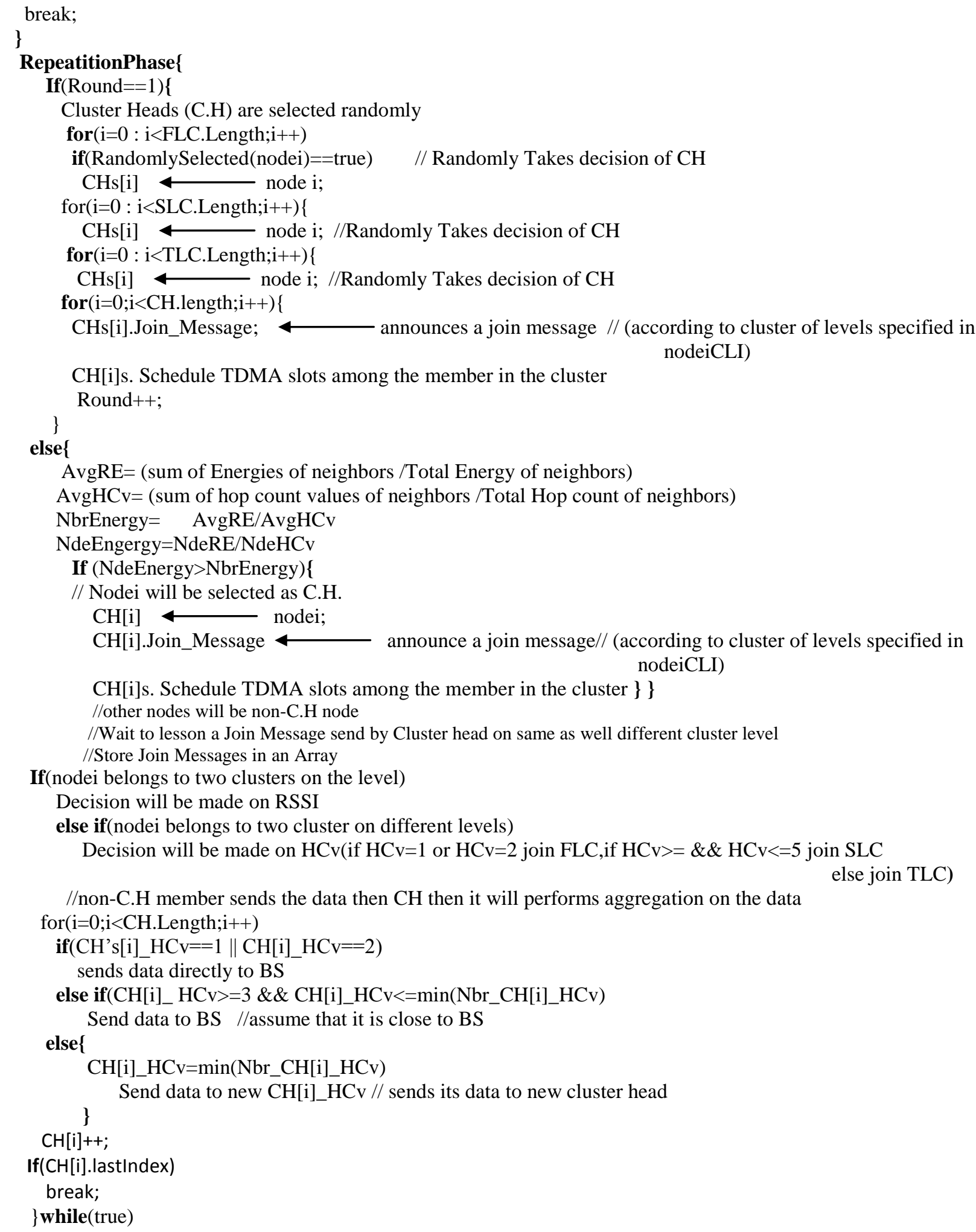

Figure 7. EEMDC's algorithm: Process of Clustering in WSNs 


\section{SIMULATION RESULTS}

Simulation results have been produced by considering the five conventional protocols namely MTE, LEACH, LEACH-C, DDAR, HEED against the proposed protocol (EEMDC). The parameters used for comparison are First Node Die Time (FNDT), Half Node Die Time (HNDT), Last Node Die Time (LNDT), Energy Consumption against Time, and number of nodes alive against Time. As we will see, in all aforementioned parameters, we will conclude that EEMDC exhibit better results than the other protocols.

\subsection{Network and Radio Model.}

All the sensor nodes have same energy at the beginning and they are densely deployed in the area. We will assume that the BS is outside the network. In the initialization phase, EEMDC protocol starts working from the BS by generating a beacon packet to help nodes to calculate its hop count value and the cluster level they belong to. After that it operates distributed and adaptively. Therefore, it avoids the congestion in the network due to distributed approach. They use the hop-count to determine the distance from the BS, and the level they belong to. They are static in nature, because they remain stationary after the deployment. Node's battery is not chargeable once it depletes its energy. Generally, the network lifetime is defined as first node failure, average node failure or last node failure. So we developed our protocol based on these cases and it is able to deem the network lifetime in terms of them. As due to hotspots problem, the nodes near the BS deplete their energy earlier than far nodes, therefore, we divide the network into three logical levels. We also assumed that each level has approximately the same number of nodes. So, for numerical purposes, first-level contains 33\%, second-level contains $33 \%$, and third-level contains the remaining $34 \%$ of nodes. The percentage of nodes being $\mathrm{CHs}$ 
in the first, second and third levels are 7\%, 4\%, and 2\% respectively. Accordingly, clusters close to the BS (first level clusters) are small in size clusters (up to 4 to 5 nodes) because they have to do their own tasks and more relay jobs. Second level clusters are one-hop bigger in size than first level clusters (about 8 to 10 nodes) because they perform lower relay tasks than first-level clusters. Third level has a maximum of 16 to 20 nodes in a cluster, because they have less probability to deplete their energy. So, overall division of the network into the three layers has amplified the network's lifetime. The connectivity of the network is such that using minimum hop count value of the $\mathrm{CH}$, third-level clusters are connected with second-level clusters, secondlevel clusters are connected with first-level, and first-level clusters drive the data to the BS.

We adopt a typical radio and energy consumption model whose specific details can be found in [44]. Communication energy consists of two factors: electronic energy and amplification energy. The electronic energy (sending and receiving) of all nodes is the same. Consequently, the factor which affects the communication energy is the amplification energy. It depends on the space of the node from the BS. There are two types of power losses: free-space ( $\mathrm{d}^{2}$ power loss) and the multi-path fading ( $\mathrm{d}^{4}$ power loss) channel. The energy exhausted for the transmission of a p-bit packet over a distance dist is given by equation 3 and 4 :

$$
\begin{array}{ll}
E_{t}\left(p, t_{\text {dist }}\right)=p E_{\text {elec }}+p \in_{\text {fs }} \text { dist }^{2} & \text { if } t<=\text { dist } \\
E_{t}\left(p, t_{\text {dist }}\right)=p E_{\text {elec }}+p \in_{m p} \text { dist }^{4} & \text { if } t_{\text {dist }}>\text { dist }
\end{array}
$$

And the radio consumes the power presented in equation 5:

$$
E_{R}(p)=p E_{\text {elec }}
$$

The notation used is included in table 3 .

\begin{tabular}{|c|c|}
\hline Simulation Parameter & Value \\
\hdashline $\mathbf{t}_{\text {dist }}$ & Transmission Distance \\
\hline
\end{tabular}




\begin{tabular}{|c|c|}
\hline $\operatorname{dist}^{2}$ & free-space Distance \\
\hline $\operatorname{dist}^{4^{-}}$ & multi-path fading \\
\hline $\mathbf{E}_{\text {elec }}$ & Electronic Energy \\
\hline $\mathbf{P}$ & p-bit packet \\
\hline Dist & Threshold distance \\
\hline$\epsilon_{\mathrm{fs}}$ & Coefficient for free-space fading \\
\hline$\in_{\mathrm{mp}}$ & Coefficient for multi-path fading \\
\hline
\end{tabular}

Table 3: Notation used in the equations

\subsection{Simulation Model}

For the performance evaluation of EEMDC, we have used OMNET++ 3.2.2 Object Oriented modular discrete event based simulator having Castalia 3.2 as the model for WSN [48-50]. The network area is about $100 \mathrm{~m} * 100 \mathrm{~m}$. We have simulated two cases: 100 nodes and 200 nodes. All these nodes have been placed randomly in the area. The division of nodes in 100 and 200 nodes cases is such that fist, second, and third levels contain equal number of nodes respectively. The initial energy of each node is fixed to 12 Joule. The packet header size is 25 bytes, the data size is 500 bytes, and the control packet size is 100 bits. We have produced the results for both 100 and 200 nodes in same network model for checking the effects of growing the number of nodes in the simulation model. See the Table 4 for each parameter's value.

\begin{tabular}{|l|c|}
\hline Simulation Parameter & Value \\
\hline Network Area & $100 \mathrm{~m} * 100 \mathrm{~m}$ \\
\hline Initial Energy & 12 Joules \\
\hline CH Percentage & 0.05 \\
\hline Packet header Size & 25 byte \\
\hline Data Size & 500 byte \\
\hline Num of Nodes & 100,200 nodes \\
\hline Simulation Time & 500 Sec \\
\hline
\end{tabular}




\begin{tabular}{|l|c|}
\hline Control Packet Size & $100 \mathrm{bit}$ \\
\hline Broadcast packet size & $25 \mathrm{bytes}$ \\
\hline Round Length & $20 \mathrm{sec}$ \\
\hline $\mathbf{E}_{\text {elec }}$ & $50 \mathrm{nj} / \mathrm{bit}$ \\
\hline $\mathbf{E}_{\mathrm{fs}}$ & $10 \mathrm{pj} / \mathrm{bit} / \mathrm{m} 4$ \\
\hline
\end{tabular}

Table 4: Network Model Parameters

\subsection{Performance Evaluation}

By using the above simulation model, EEMDC is evaluated against five conventional protocols such as LEAC, LEACH-C, MTE, DDAR, and HEED. The following five performance metrics have been considered for evaluating EEMDC protocol against the conventional protocols.

- First Node Die Time (FND): Time when first node is died in the network

- Half Node Die Time (HND): Time when half nodes died in the network

- Last Node Die Time (LND): Time when last node died in the network

- Energy Consumption over Simulation Time (ECoST): Energy consumed by nodes with respect to simulation time

- Number of Alive Nodes over Simulation Time (NAoST): Represents the total number of nodes alive regarding to the simulation time.

Fig. 8 and Fig. 9 show the FND Time in case of 100 and 200 nodes. Fig. 8, shows that, for 100 nodes, the die time for the first node is 16.5152 seconds in EEMDC, whereas the die time for the first nodes are 8.35 sec., 10.96 sec., 13.25 sec., 14.77 sec., and 15.12 sec. for MTE, LEACH, LEACH-C, DDAR, and HEED respectively. When we increase the number of nodes up to 200 (see Fig. 9), for EEMDC protocol the first node died at 15.12 seconds, while the die time for the first node of the studied protocols (MTE, LEACH, LEACH-C, DDAR, and HEED) are $5.35 \mathrm{sec}$., $8.96 \mathrm{sec}, 10.25 \mathrm{sec} ., 12.77 \mathrm{sec}$. , and $14.12 \mathrm{sec}$. respectively. 


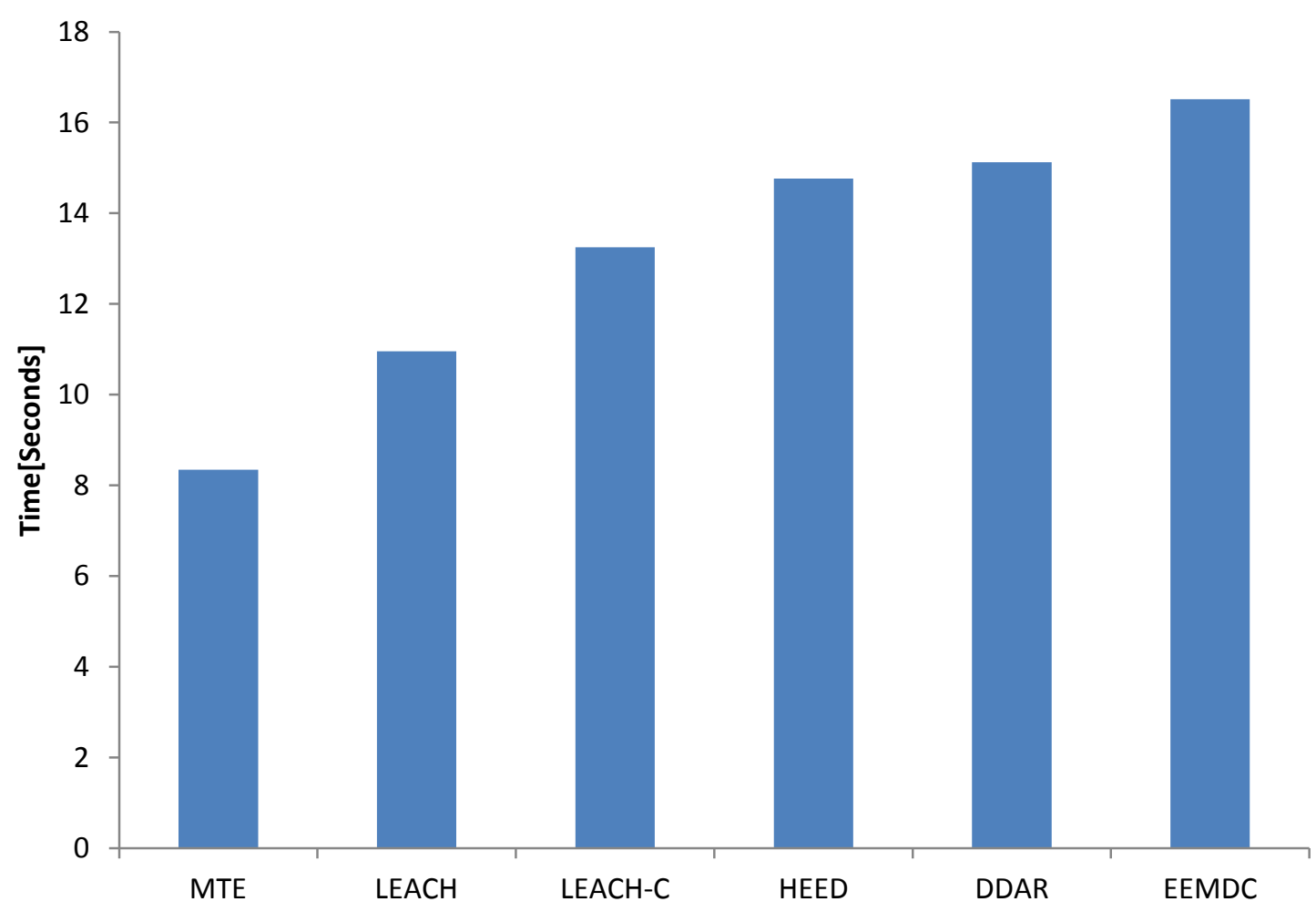

Figure 8: Total 100 Nodes: First Node Die (FND) over Simulation Time [Seconds] 


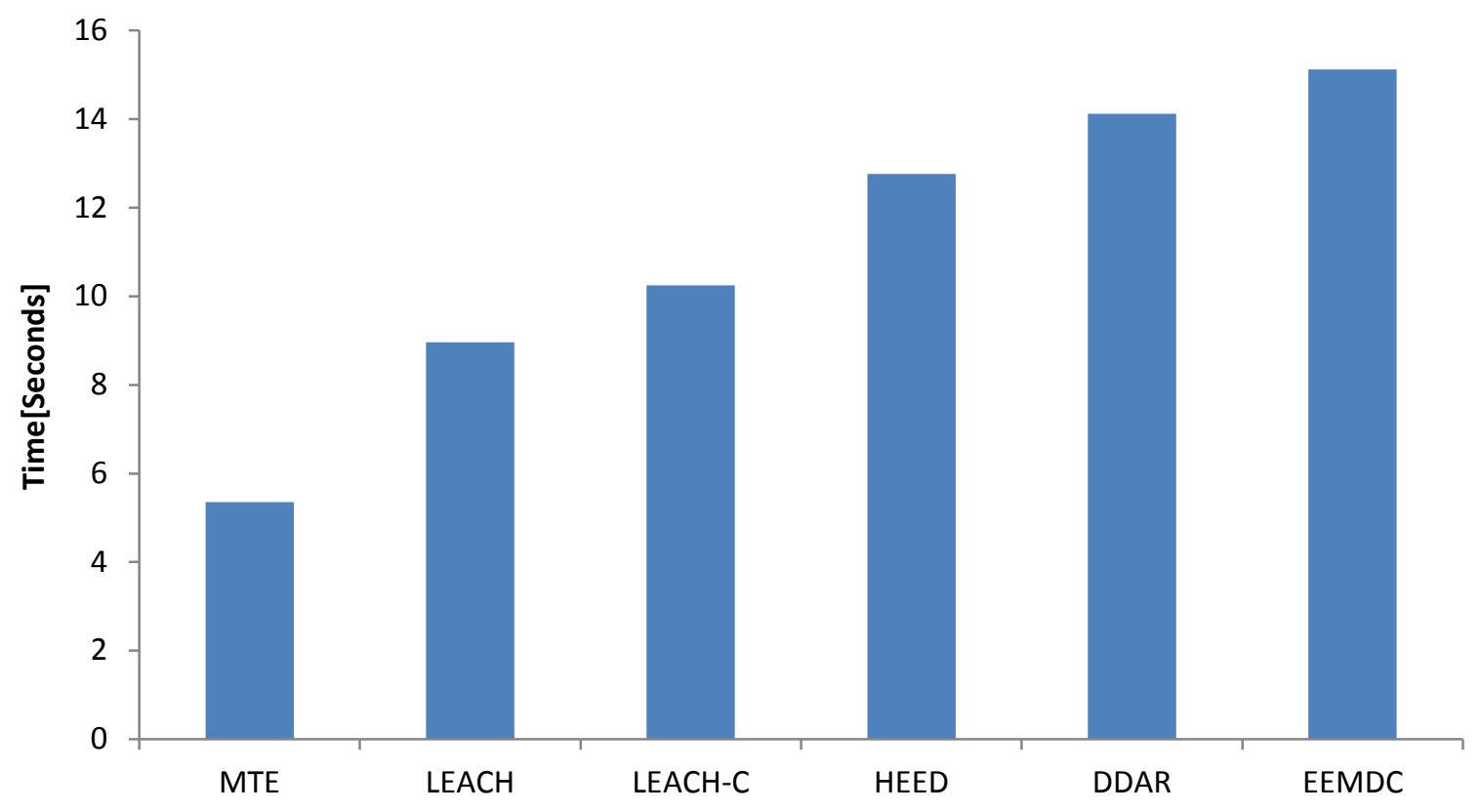

Figure 9: Total 200 Nodes: First Node Die (FND) over Simulation Time [Second]

Fig. 10 and Fig. 11 show the HND Time in case of 100 and 200 nodes. Fig. 11 demonstrates that, for 100 nodes, $50 \%$ of the nodes died at 764.996 seconds in EEMDC, whereas half nodes died at 350.46 sec., 399.92 sec., 590.5 sec., 601.3 sec. and 799.78 sec. in case of MTE, LEACH, LEACH-C, DDAR, and HEED respectively. When we increase the number of nodes up to 200, the die time for the half nodes of the studied protocols (MTE,LEACH,LEACH-C,HEED, and DDAR) are $213.46 \mathrm{sec} ., 299.22 \mathrm{sec} ., 350.35 \mathrm{sec} ., 401.3 \mathrm{sec}$. and $523.78 \mathrm{sec}$. respectively, while half nodes died at 604.0 sec. in EEMDC protocol (see Fig. 11). 


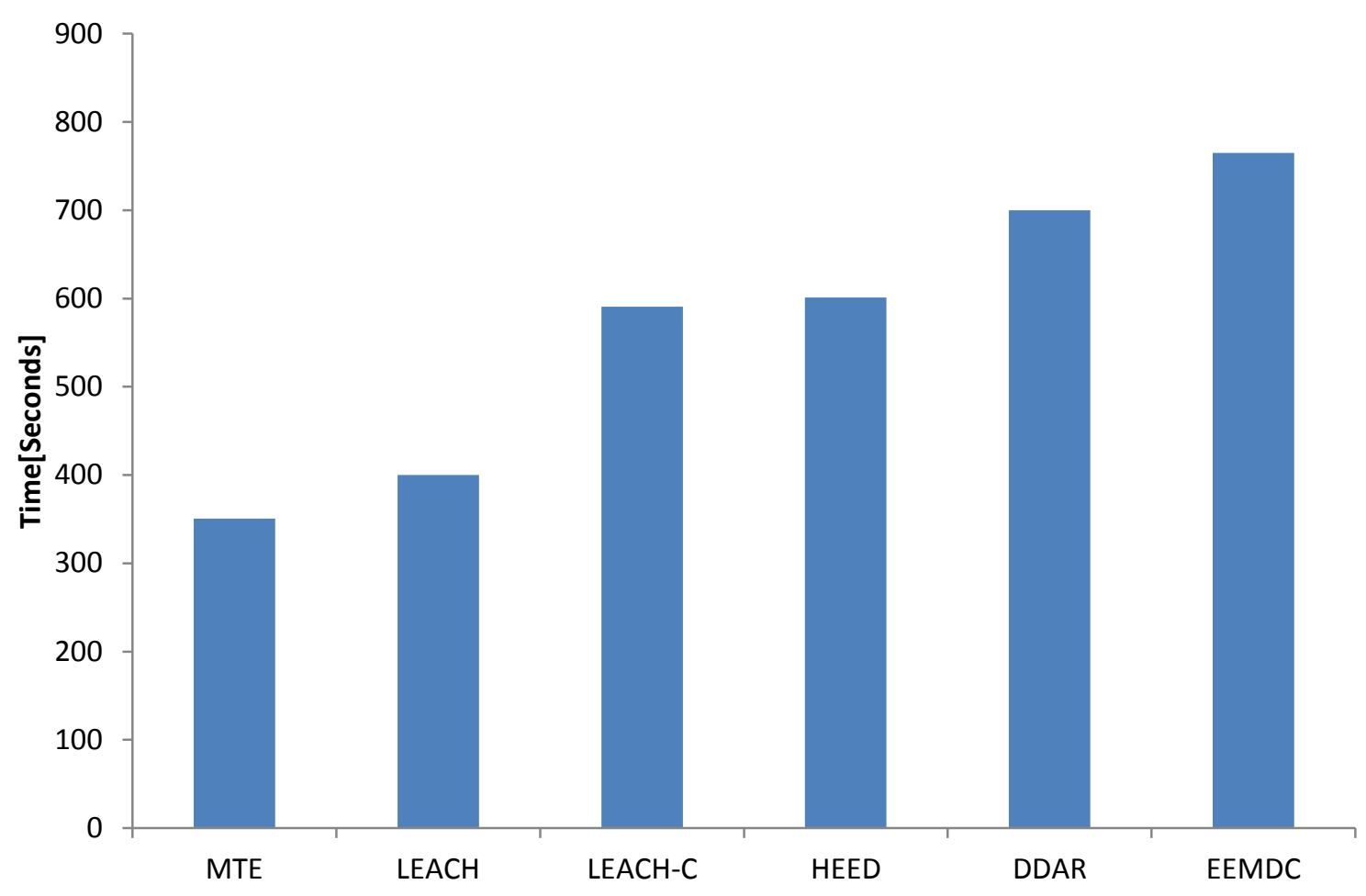

Figure 10: Total 100 Nodes Half Node Die (HND) over Simulation Time [Second]

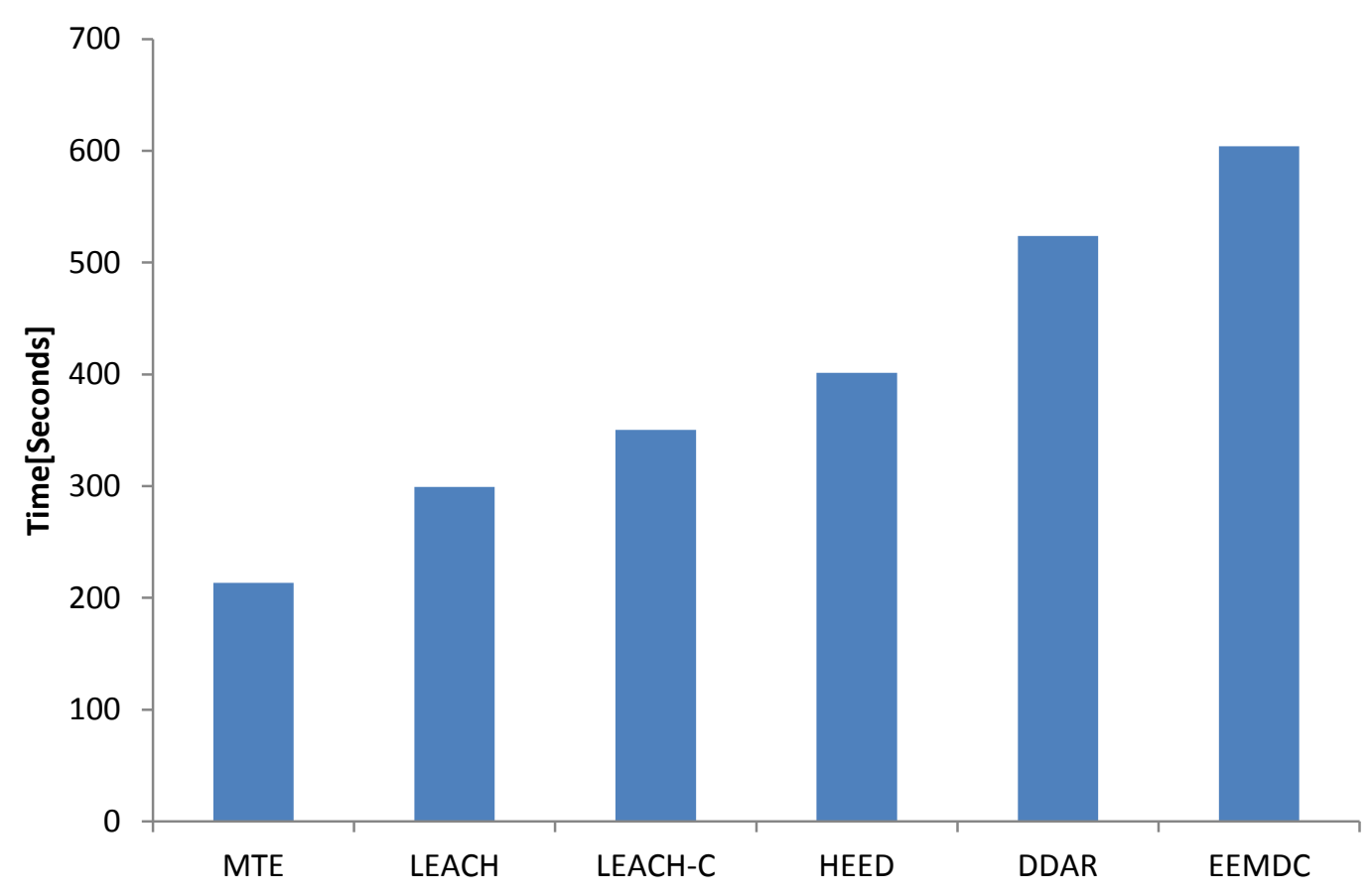

Figure 11: Total 200 Nodes Half Node Die (HND) over Simulation Time [Second] 
Fig. 12 provides LND when there are 100 nodes in the WSN. It provides for MTE, LEACH, LEACH-C, HEED, and DDAR a LND time of $460.92 \mathrm{sec} ., 465.84 \mathrm{sec} ., 706.34 \mathrm{sec} ., 999.6 \mathrm{sec}$., and $1109.79 \mathrm{sec}$. respectively, while we have obtained $123.52 \mathrm{sec}$. for EEMDC.

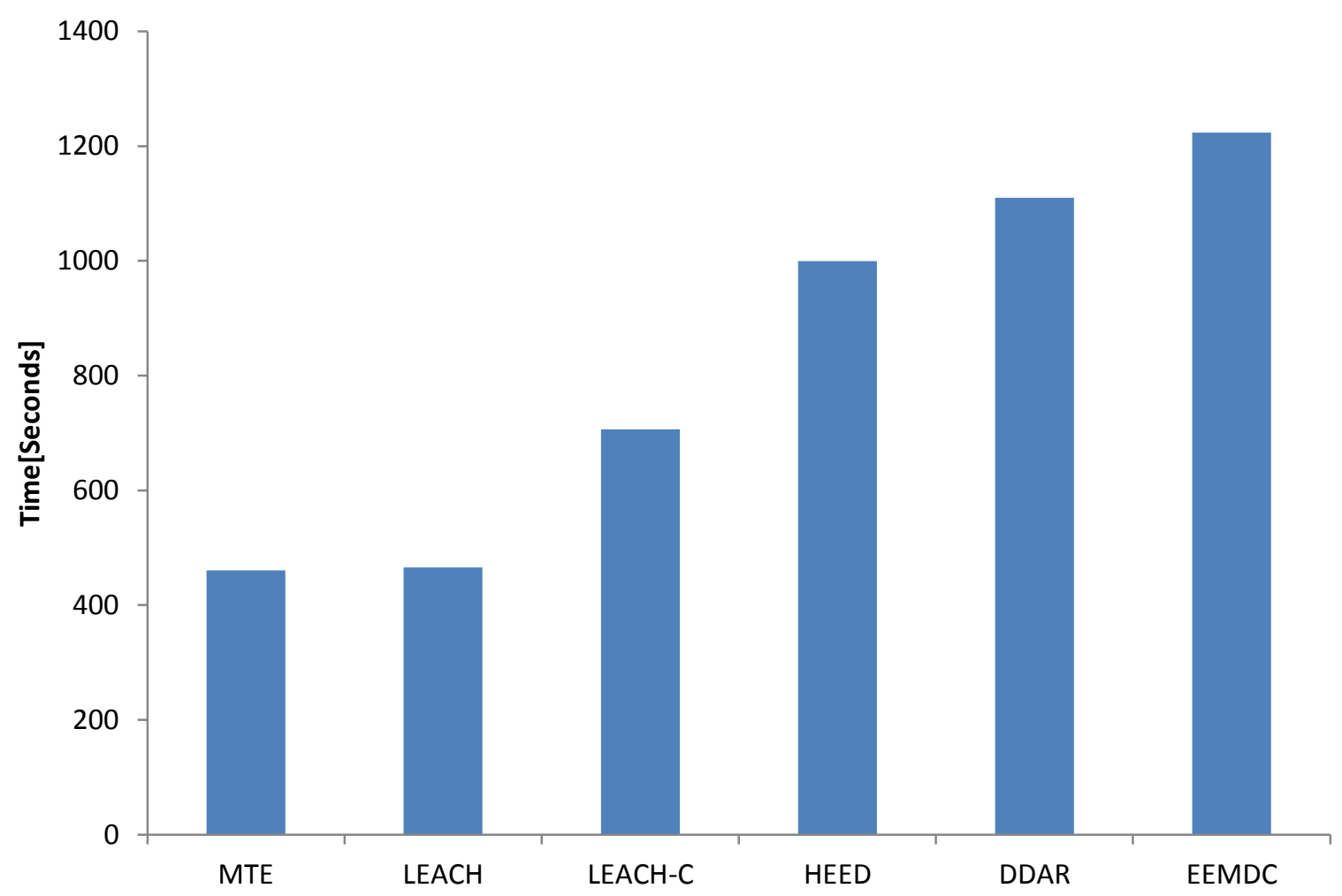

Figure 12: Total 100 Nodes: Last Node Die (LND) over Simulation Time [Second]

Similarly, when the numbers of nodes increase in the WSN the LND time drops to 305.92 sec., 365.84 sec., 586.34 sec., 645.6 sec., and 704.79 sec. in MTE, LEACH, LEACH-C, DDAR, and HEED respectively, whereas we obtained 1099.52 sec. for EEMDC protocol. This can be seen in Figure 13.

Fig. 14 shows the energy consumption of the studied protocols along the time. The simulation results shows that EEMDC consumes $69.346 \%$ less energy than MTE, 27.32\% less energy than 
LEACH, $17.028 \%$ less energy than LEACH-C, $12.1 \%$ less energy than HEED, and $4.4356 \%$ less energy than DDAR. So, EEMDC is better than the other protocols.

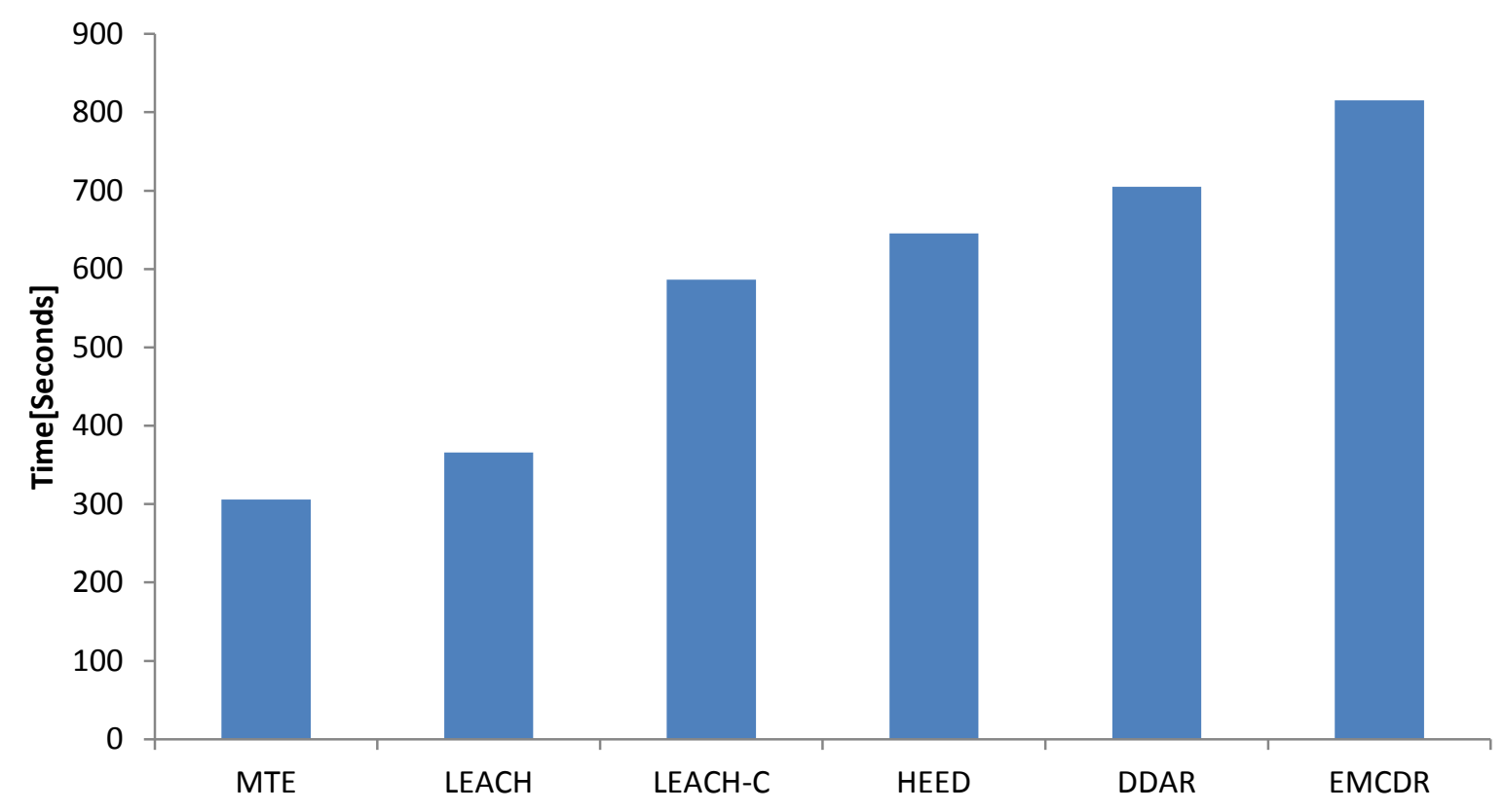

Figure 13: Total 200 Nodes: First Node Die (FND) over Simulation Time [Second] 




Figure 14: Energy Consumed by Nodes over Simulation Time [Second]

Fig. 15 shows the number of nodes alive along the time. This simulation shows that the proposed protocol have 97 nodes alive after 500 seconds. But MTE, LEACH, LEACH-C, HEED, and DDAR have $6,9,84,90,94$ of nodes alive respectively after 500 seconds. 


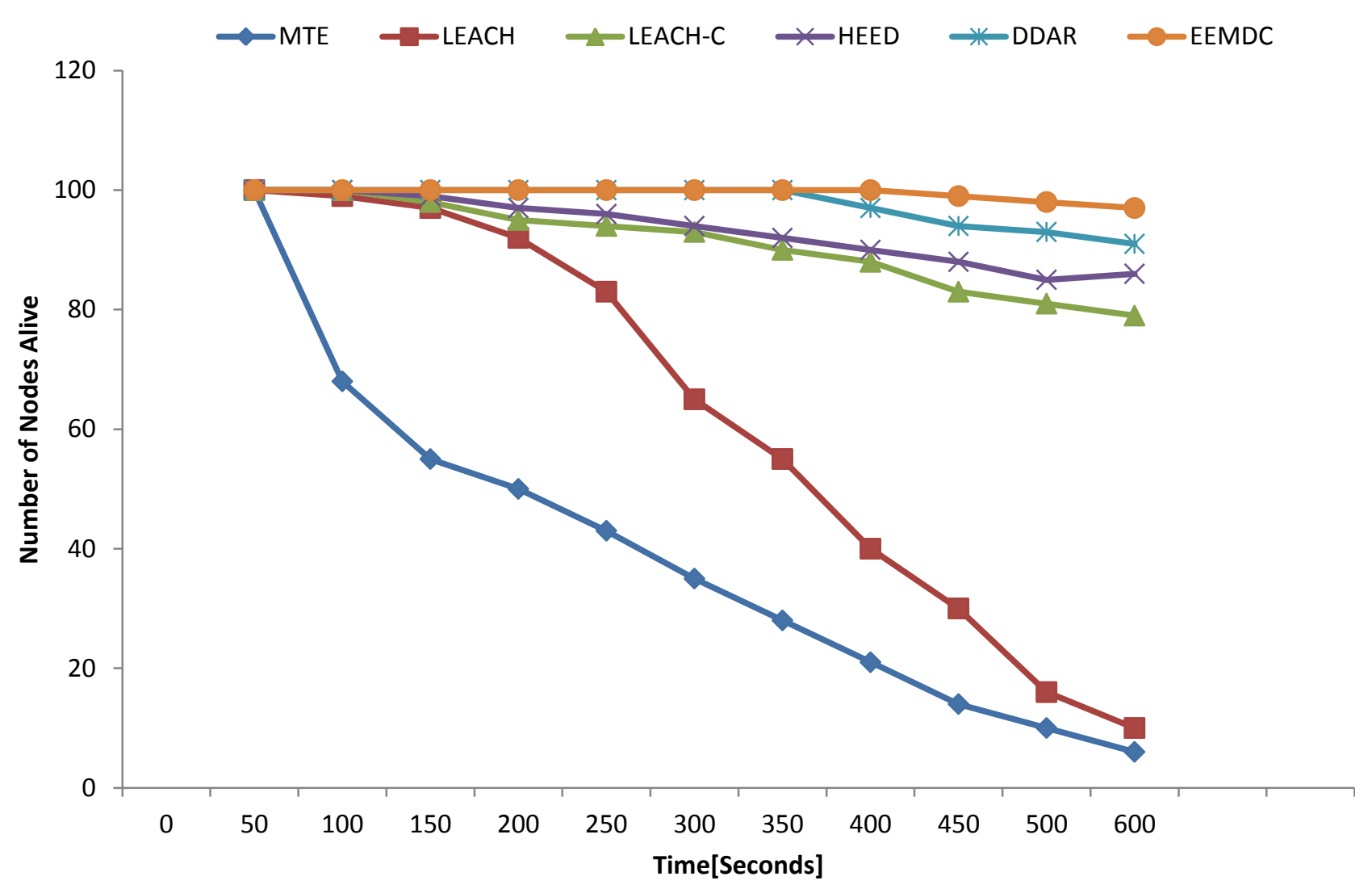

Figure 15: Number of Nodes alive over Simulation Time [Second]

\section{CONCLUSION}

The EEMDC is an energy efficient multi-level clustering routing protocol. It attempts to increase the network lifetime, while provides more stability and reliability to the network. The distinctive characteristics of EEMDC, which makes this protocol different from conventional protocols, are the following ones:

- It divides the network area into three logical layers. By doing the partition of the network area, the hotspot problem is fixed.

- The distance of the nodes to the $\mathrm{CH}$ and the $\mathrm{CH}$ to the $\mathrm{BS}$ are taken into account when considering the hop-count value of the nodes.

- $\mathrm{CH}$ is elected by acquiring the average left-over energy of the nodes. 
- The fused-data is delivered to the BS using the minimum distance path to the BS (in terms of hop count values).

All these four features are not collectively taken into account in any traditional protocols such as LEACH, LEACH-C, MTE, DDAR and HEED.

The simulation results show that EEMDC achieves greater energy efficiency compared to conventional protocols, thus the network lifetime is increased.

In future works we are going to include security in our system by using efficient authentication processes [47] and combine our energy-efficient clustering technique with artificial neural networks in order to prevent energy exhaustion attacks [48]. Moreover, we will include data fusion techniques in our deployment.

\section{ACKNOWLEDGEMENTS}

This work has been partially carried by the "Ministerio de Ciencia e Innovación", through the "Plan Nacional de I+D+i 2008-2011" in the "Subprograma de Proyectos de Investigación Fundamental", project TEC2011-27516, and by the Polytechnic University of Valencia, though the PAID-15-11 multidisciplinary projects.

\section{REFERENCES}

[1] S. Sendra, J. Lloret, M. Garcia, J. F. Toledo, (2011). "Power Saving And Energy Optimization Techniques For Wireless Sensor Networks", Journal of Communications, Vol. 6, Issue 6, pp. 439-459, doi:10.4304/jcm.6.6.439-459

[2] D. Bri, M. Garcia, J. Lloret, P. Dini, Real, (2009). "Deployments of Wireless Sensor Networks", Third International Conference on Sensor Technologies and Applications, SENSORCOMM 2009. Athens, Greece. 8-23. 
[3] M. Garcia, D Bri, S. Sendra, J. Lloret, (2010). "Practical Deployments Of Wireless Sensor Networks: A Survey", International Journal on Advances in Networks and Services Vol. 3, No. 1\&2, pp. 170-185.

[4] L. GUI, T. VAL, A. WEI, (2011). "A Novel Two-Class Localization Algorithm in Wireless Sensor Networks, Network Protocols and Algorithms”, Vol. 3, No. 3 , pp. 1-16

[5] F. Ghofrane, L. Wassef, J. M. Ben, (2010). "Energy-aware Virtual Ring Routing in Wireless Sensor Networks", Network Protocols and Algorithms, Vol. 2, No. 4, pp. 16-29.

[6] A. Rajeswari, P. T. Kalaivaani, (2011). "A Novel Energy Efficient Routing Protocols for Wireless Sensor Networks Using Spatial Correlation Based Collaborative Medium Access Control Combined with Hybrid MAC", Network Protocols and Algorithms, Vol. 3, No. 4, pp. 1-17.

[7] J. Lloret, M. Garcia, J. Tomás, F. Boronat. (2008). "GBP-WAHSN: A Group-Based Protocol for Large Wireless Ad Hoc and Sensor Networks", Journal of Computer Science and Technology, Vol. 23, No. 3. pp. 461-480.

[8] J. Lloret, M. Garcia, D. Bri, J. R. Diaz, (2009). "A Cluster-Based Architecture to Structure the Topology of Parallel Wireless Sensor Networks", Sensors, Vol. 9, No. 12. pp. 1051310544.

[9] M. Lehsaini, H. Guyennet, M. Feham, (2010). "Cluster-based Energy-efficient k-Coverage for Wireless Sensor Networks", Network Protocols and Algorithms, Vol. 2, No. 2, pp. 89106.

[10] H. Safa, O. Mirza, (2010). "A load balancing energy efficient clustering algorithm for MANETs", International Journal of Communication Systems, Vol. 23, No. 4, pp. 463-483. DOI: $10.1002 /$ dac. 1084

[11] G. Liu1, B. Xu, H. Chen, (2012). "Decentralized estimation over noisy channels in clusterbased wireless sensor networks", International Journal of Communication Systems, Vol. 25, No. 10, pages 1313-1329.

[12] K. A. Ur Rehman, M. Sajjad, H. Khizar, K. S. Ullah, (2012). "Clustering-based powercontrolled routing for mobile wireless sensor networks", International Journal of Communication Systems, Vol. 4, No. 25, pp. 529-542. 
[13] L. Cheng, C. Chen, J. Ma, L. Shu, (2012). "Contention-based geographic forwarding in asynchronous duty-cycled wireless sensor networks", International Journal of Communication Systems, Vol. 25, N0. 12, pp. 1585-1602.

[14] X. Wang, H. Qian, (2012). "Hierarchical and low-power IPv6 address configuration for wireless sensor networks", International Journal of Communication Systems, Vol. 25, No. 12, pp. 1513-1529.

[15] D. Zhang, Z. Yang, V. Raychoudhury, Z. Chen, J. Lloret, (2013). "An Energy-Efficient Routing Protocol Using Movement Trends in Vehicular Ad hoc Networks". Computer. Journal. Vol. 56 , No. 8, pp. 938-946.

[16] R. V. Biradar, V. C. Patil, Dr. S. R. Sawant, Dr. R. R. Mudholkar, (2009). "Classification and Comparison of Routing Protocols in Wireless Sensor Networks", Ubiquitous Computing and Communication Journal, Vol. 4, pp.704-711.

[17] J. Chen, Z. Hong, N. Wang, S. Jhuang, (2010). "Efficient Cluster Head Selection Methods for Wireless Sensor Networks”, Journal of Networks, Vol. 5, pp. 964-970.

[18] A. Peiravi, H. R. Mashhadi, S. H. Javadi, (2013). "An Optimal Energy-Efficient Clustering Method In Wireless Sensor Networks Using Multi-Objective Genetic Algorithm", International Journal of Communication Systems, Volume 26, No. 1, Pp. 114-126.

[19] M. Zeynali, A. Mollanejad, L.M. Khanli, (2011). "Novel Hierarchical Routing Protocol in Wireless Sensor Network" Procedia Computer Science, Vol. 3, pp. 292-300.

[20] J. Chen, Z. Hong, N. Wang, S. Jhuang, (2010). "Efficient Cluster Head Selection Methods for Wireless Sensor Networks", Journal of Networks, Vol. 5, pp. 964-970.

[21] W. Heinzelman, A. Chandrakasan, H. Balakrishnan, (2000). "Energy-Efficient Communication Protocol for Wireless Microsensor Networks", In 33rd Hawaii International Conference on System Sciences (HICSS), pp. 3005-3014.

[22] G. S. Chhabra, D. Sharma, (2011). "Cluster-Tree based Data Gathering in Wireless Sensor Network", International Journal of Soft Computing and Engineering (IJSCE), Vol. 1, No.1.

[23] A. Wang, D. Yang, D. Sun, (2012). "A Clustering Algorithm Based On Energy Information And Cluster Heads Expectation for Wireless Sensor Networks", Computers \& Electrical Engineering, Vol. 38, No. 3, pp. 662-671. 
[24] H. Gou, Y. Yoo, (2010). "An Energy Balancing LEACH Algorithm for Wireless Sensor Networks. In: Proc", 7th international conference on information technology: new generations (ITNG), Las Vegas, Nevada, USA.

[25] P. Ding, J. Holliday, A. Celik, (2005). "Distributed Energy-Efficient Hierarchical Clustering for Wireless Sensor Networks", Lecture Notes in Computer Science, Vol. 20, pp. $322-339$.

[26] S. Bandyopadhyay, E. Coyle, (2003). "An Energy-Efficient Hierarchical Clustering Algorithm for Wireless Sensor Networks", The 32nd IEEE International Conference on Computer Communication (INFOCOM 2003), Turin (Italy), April 14-19, 2013.

[27] A. Jarry, P. Leone, S. Nikoletseas, J. Rolim, (2011). "Optimal Data Gathering Paths and Energy-Balance Mechanisms in Wireless Networks", Ad Hoc Networks, Vol. 9, Issue 6, pp. 1036-1048.

[28] Yi-hua Zhu, Wan-deng Wu, Jian Pan, Yi- ping Tang, (2010). "An Energy-Efficient Data Gathering Algorithm to Prolong Lifetime Of Wireless Sensor Networks", Computer Communications, Volume 33, No. 5, pp.639-647.

[29] Khamfroush, H., Saadat, R., Khademzadeh, A., Khamfroush, Keyhan, (2009). "Lifetime Increase for Wireless Sensor Networks Using Cluster-Based Routing", International Association of Computer Science and Information Technology - Spring Conference (IACSIT-SC 2009), Singapore, Apr. 2009.

[30] Li H., Liu Y., Chen W., Jia W., Li B., Xiong J, (2013). "COCA: Constructing Optimal Clustering Architecture to Maximize Sensor Network Lifetime", Computer Communications, Volume 36, No. 3, pp. 256-268.

[31] Aslam, N., Phillips, W., Robertson, W., Sivakumar, S, (2007). "A Multi-Criterion Optimization Technique for Energy Efficient Cluster Formation in Wireless Sensor Networks", $4^{\text {th }}$ IEEE Consumer Communications and Networking Conference, (CCNC 2007). pp. $650-654$.

[32] S. Yi, J. Heo, Y. Cho, J. Hong, (2007). PEACH: "Power-Efficient and Adaptive Clustering Hierarchy Protocol for Wireless Sensor Networks", Computer Communications, Vol. 30, pp. $2842-2852$. 
[33] Z. Yong and Q. Pei, (2012). "A Energy-Efficient Clustering Routing Algorithm Based On Distance And Residual Energy For Wireless Sensor Networks," Procedia Engineering, vol. 29, 2012, pp. 1882-1888.

[34] W. Chuan-Chi, (2011). "A Minimum Transmission Energy Consumption Routing Protocol For User-Centric Wireless Networks", IEEE/SICE International Symposium System Integration (SII 2011), pp. 1143 - 1148.

[35] O. Younis, S.Fahmy, (2004). HEED: “A Hybrid, Energy-Efficient, Distributed Clustering Approach For Ad Hoc Sensor Networks", Transactions on Mobile Computing, Vol. 3, pp. 660-669.

[36] D. Kumar, T. C. Aseri, R.B. Patel, (2008). "EEHC : Energy Efficient Heterogeneous Clustered Scheme for Wireless Sensor Networks", Computer Communications, Vol. 32, pp. $662-667$

[37] K. T. Kim, S. S. Moon, (2010). "Tree-Based Clustering (TBC) for Energy Efficient Wireless Sensor Networks", IEEE 24th International Conference on Advanced Information Networking and Applications Workshops (WAINA) Perth, WA, pp. 680685,10.1109/WAINA.2010.62.

[38] Yu J, Qi Y et al. (2012). "A Cluster-Based Routing Protocol for Wireless Sensor Networks With Nonuniform Node Distribution", AEU-International Journal of Electronics and Communications, Vol. 66, No. 1, pp. 54-61.

[39] M. Ye,C. LI, J. WuEECS: (2005). "An Energy Efficient Clustering Scheme in Wireless Sensor Networks" , 24th IEEE International Performance on Computing, and Communications Conference, pp. 535-540, 10.1109/PCCC.2005.1460630

[40] N. Gautama, W. Lee, J. Pyun, (2009). "Dynamic Clustering and Distance Aware Routing Protocol for Wireless Sensor Networks", PE-WASUN'09 , pp. 28-29, Tenerife, Canary Islands, Spain.

[41] W. Heinzelman, H. Chandrakasan, A. Balakrishnan, (2002). "An Application-Specific Protocol Architecture for Wireless Microsensor Networks", IEEE Transactions on Wireless Communications, Vol-1, pp. 660-670.

[42] W. K. Lai, C. S. Fan, Y. L. Lin, (2012). “Arranging Cluster Sizes and Transmission Ranges for Wireless Sensor Networks", Information Sciences, Vol.183, No.1, pp. 117-131 
[43] N. A. Pantazis, D. J. Vergados, D. D. Vergados, C. Douligeris. (2009). "Energy Efficiency in Wireless Sensor Networks Using Sleep Mode TDMA Scheduling", Ad Hoc Networks, pp. 322-343.

[44] N. Meghanathan, (2012). "Link Expiration Time and Minimum Distance Spanning Trees based Distributed Data Gathering Algorithms for Wireless Mobile Sensor Networks", International Journal of Communication Networks and Information Security (IJCNIS), Vol. 4, No. 3, pp. 22-36.

[45] A. M. Popescu, G. I. Tudorache, B. Peng, A. H. Kemp, (2012). "Surveying Position Based Routing Protocols for Wireless Sensor and Ad-hoc Networks", International Journal of Communication Networks and Information Security (IJCNIS), Vol. 4, No. 1, pp. 41-67.

[46] O. A. Fdili, Y. Fakhri, D. Aboutajdine, (2012). "Impact Of Queue Buffer Size Awareness On Single And Multi Service Real-Time Routing Protocols For WSNs", International Journal of Communication Networks and Information Security (IJCNIS), Vol. 4, No. 2, pp. 104-111.

[47] M. Hussaini, H. B. Salau, A. F. Salami, F. Anwar, A. H. Abdalla, M. R. Islam, (2012). "Enhanced Clustering Routing Protocol for Power-Efficient Gathering in Wireless Sensor Network", International Journal of Communication Networks and Information Security (IJCNIS), Vol. 4, No. 1, pp. 18-28.

[48] Documentation and Tutorials of omnet++. http://www.omnetpp.org/ (last accessed date: 10 Mar, 2013).

[49] Documentation and Tutorials of Castalia Simulator for WSN and BAN. http://castalia.research.nicta.com.au/index.php/en/ (last accessed date: 15 Mar 2013).

[50] Download Leach v2 for Castalia http://www.gercom.ufpa.br/index.php?option=com_filecabinet\&view=files\&id=1\&Itemid=3 1\&lang=pt (last accessed date: 15 Mar 2013). 